\title{
LOS ACUERDOS DE CANCÚN: UN NUEVO IMPULSO A LAS NEGOCIACIONES INTERNACIONALES SOBRE CAMBIO CLIMÁTICO
}

\author{
Paola Milenka Villavicencio Calzadilla ${ }^{*}$ \\ Becaria predoctoral \\ Universitat Rovira i Virgili \\ p_villavicencio@hotmail.com
}

Recibido: 22 de marzo de 2011 / Aceptado: 4 de mayo de 2011

RESUMEN: Aunque los pronósticos se inclinaban por un nuevo fracaso tras la oposición de Bolivia, finalmente las delegaciones de los Estados que participaron en la XVI Conferencia de las Partes de la Convención Marco de Naciones Unidas sobre Cambio Climático (COP16) y la VI Conferencia de las Partes del Protocolo de Kioto (COP/MOP6) lograron concretar su trabajo en un acuerdo general que fija las bases de un futuro acuerdo vinculante y global sobre el cambio climático — los Acuerdos de Cancún-, lo que demostró que un proceso de negociación transparente e incluyente es el elemento fundamental para recobrar la confianza y reafirmar el compromiso de lucha contra el cambio climático. Sin embargo, parece que la tarea solo ha comenzado.

RESUM: Encara que els vaticinis s'inclinaven per un nou fracàs després de l'oposició de Bolívia, finalment les delegacions dels Estats que van participar en la XVI Conferència de les Parts de la Convenció Marc de Nacions Unides sobre canvi climàtic (COP16) i la VI Conferència de les Parts del Protocol de Kioto (COP/MOP6) van aconseguir concretar el seu treball en un acord general que fixa les bases d'un futur acord vinculant i global sobre el canvi climàtic - els "Acords de Cancún" - demostrant

\footnotetext{
*** Becaria predoctoral del Ministerio de Asuntos Exteriores y de Cooperación de España y la Agencia Española de Cooperación Internacional para el Desarrollo (MAEC-AECID), adscrita al Departamento de Derecho Público, Universidad Rovira i Virgili (URV), y al Centro de Estudios de Derecho Ambiental de Tarragona (CEDAT).
} 
que un procés de negociació transparent i incloent és l'element fonamental per a recuperar la confiança i reafirmar el compromís de lluita contra el canvi climàtic. No obstant això, sembla que la tasca només ha començat.

ABSTRACT: Although the predictions were inclined to a new failure after Bolivia's opposition, finally the State delegations that participated in the XVI Conference of the Parties to the United Nations Framework Convention on Climate Change (COP16) and the Sixth Conference of the Parties Kyoto Protocol (COP/MOP6) managed to realize their work in a general agreement that lays the groundwork for a future global binding agreement on climate change - "The Cancun Agreements" - demonstrating that a negotiation process transparent and inclusive is the key to restore confidence and reaffirm commitment to combat climate change. However, it seems that the task has only begun.

PALABRAS CLAVE: cambio climático - conferencia de las partes - Acuerdos de Cancún.

PARAULES CLAU: Canvi Climàtic - Conferència de les Parts - Acords de Cancún.

KEYWORDS: Climate Change - Conference of the Parties - Cancun Agreements.

Sumario: I. Introducción. Copenhague, el fracaso como experiencia. II. La COP16: Un difícil proceso de negociación. El rechazo de Bolivia. 1. Los Acuerdos de Cancún, ¿reciclaje del Acuerdo de Copenhague? 2. El consenso, ¿unánime? III. Los Acuerdos de Cancún, ¿una nueva era de cooperación internacional? 1. Mitigación. 2. Financiación. 3. Mecanismo de tecnología. 4. Mecanismo REDD+. 5. Mercado de carbono. 6. Adaptación. 7. Creación y fortalecimiento de capacidades. 8. Revisión. 9. Otros asuntos. IV. A manera de conclusiones: ¿Qué deja Cancún y qué se espera en Durban? V. Bibliografía. 1. Referencias doctrinales. 2. Referencias normativas. 3. Referencias documentales. Anexo I: Similitudes entre el Acuerdo de Copenhague y los Acuerdos de Cancún. Anexo II: Elementos primordiales de los "Acuerdos de Cancún".

\section{INTRODUCCIÓN. COPENHAGUE, EL FRACASO COMO EXPERIENCIA}

Las conclusiones de la XV Conferencia de las Naciones Unidas sobre el Cambio Climático (en adelante, COP15) celebrada en diciembre de 2009 en Copenhague, 
Dinamarca, solo demostraron a la comunidad internacional que las negociaciones sobre el cambio climático deberán afrontar un difícil camino antes de lograr la suscripción de cualquier acuerdo jurídicamente vinculante. Precisamente fue el Acuerdo de Copenhague $^{1}$ el que generó un ambiente de desconfianza en la sociedad civil, pues una vez más en la historia de las negociaciones, el poder de algunas naciones y líderes políticos se antepuso al bienestar de toda la humanidad ${ }^{2}$.

A este ambiente desalentador se suma el hecho de que con la creación de dos grupos ad hoc, a saber, el Grupo de Trabajo Especial sobre los futuros compromisos de las partes

\footnotetext{
${ }^{1}$ La XV Conferencia de Naciones Unidas sobre el Cambio Climático y el V período de sesiones de la Conferencia de las Partes, que sirvió como reunión de las partes del Protocolo de Kioto, desarrollado en Copenhague del 7 al 18 de diciembre de 2009, tuvieron como resultado el denominado Acuerdo de Copenhague. Vid. Decisión 2/CP.15 del doc. FCCC/CP/2009/11/Add.1 de 30 de marzo de 2010, pp. 5-10. $\begin{array}{llllll}\text { Recuperado el } & 20 & \text { de } & \text { de } & \end{array}$ http://unfecc.int/resource/docs/2009/cop15/spa/11a01s.pdf\#page $=4$
}

Es importante señalar que dentro del sistema jurídico internacional, el término acuerdo se utiliza generalmente como una denominación de instrumentos jurídicos internacionales que denotan la existencia de un tratado, tal como lo establece la Convención de Viena sobre el Derecho de los Tratados de 1969 (artículo 1.1 definiciones). Sin embargo, el Acuerdo de Copenhague, al no haber sido adoptado por consenso por los miembros de la Conferencia de las Partes de la CMNUCC, carece de las condiciones necesarias para ser un instrumento jurídicamente vinculante que tenga la condición de acuerdo internacional. Cabe mencionar que la COP no cuenta con un reglamento de procedimiento aprobado, razón por la que se aplica el documento FCCC/CP/1996/2 del Proyecto de Reglamento de 22 de mayo de 1996, con la excepción del proyecto de regla 42 sobre la votación. En este sentido, la COP continúa aplicando la regla del consenso establecida por dicho documento, a la espera de alcanzar algún día el consenso sobre el artículo 42 de este proyecto, que permitiría adoptar las decisiones mediante voto mayoritario. Vid. Estrada, R., "Acuerdo de Copenhague: las negociaciones sobre el cambio climático después de la XV Conferencia” en Revista del Centro de Economía Internacional, núm. 17, 2010, p. 114115. Recuperado el 22 de septiembre de 2010, de:_http://www.cei.gov.ar/revista/17/parte5b.pdf

${ }^{2} \mathrm{Si}$ bien el Acuerdo de Copenhague es un documento político que refleja la opinión de un grupo de países importantes, a saber, Estados Unidos, China, India, Brasil y Sudáfrica, otros 141 países han expresado su intención de aceptarlo: Afganistán, Albania, Alemania, Angola, Antigua y Barbuda, Argelia, Armenia, Australia, Austria, Bahamas, Bangladesh, Barbados, Bélgica, Belice, Benín, Bielorrusia, Bosnia y Herzegovina, Botsuana, Brasil, Brunéi, Bulgaria, Burkina Faso, Burundi, Bután, Cabo Verde, Camboya, Camerún, Canadá, República Centroafricana, Chad, República Checa, Chile, China, Chipre, Colombia, Comoras, República del Congo, República Democrática del Congo, República de Corea, Costa de Marfil, Costa Rica, Croacia, Dinamarca, Emiratos Árabes Unidos, Eritrea, Eslovaquia, Eslovenia, España, Estados Unidos de América, Estonia, Etiopía, Finlandia, Francia, Fiyi, Gabón, Gambia, Georgia, Ghana, Grecia, Guatemala, Guinea, Guinea-Bissau, Guyana, Honduras, Hungría, India, Indonesia, Irlanda, Islandia, Israel, Italia, Jamaica, Japón, Jordania, Kazajistán, Kenia, Kiribati, Laos, Lesoto, Letonia, Liberia, Liechtenstein, Lituania, Luxemburgo, la ex República Yugoslava de Macedonia, Madagascar, Malaui, Maldivas, Malí, Malta, Marruecos, Islas Marshall, Mauricio, Mauritania, México, Moldavia, Mónaco, Mongolia, Montenegro, Mozambique, Namibia, Nepal, Nigeria, Noruega, Nueva Zelanda, Países Bajos, Palau, Panamá, Papúa-Nueva Guinea, Perú, Polonia, Portugal, Reino Unido de Gran Bretaña e Irlanda del Norte, Ruanda, Rumania, Federación de Rusia, Samoa, San Marino, Santa Lucía, Senegal, Serbia, Sierra Leona, Singapur, Suazilandia, Sudáfrica, Suecia, Suiza, Tanzania, Tayikistán, Timor-Leste, Togo, Tonga, Trinidad y Tobago, Túnez, Ucrania, Uganda, Unión Europea, Uruguay, Vietnam, Yibuti y Zambia. Vid. portal oficial de la CMNUCC http://unfecc.int. Última visita 6 de mayo de 2011 . 
del anexo I con arreglo al Protocolo de Kioto (en adelante, GTE-PK ${ }^{3}$ ) y el Grupo de Trabajo Especial sobre la cooperación a largo plazo en el marco de la Convención Marco de Naciones Unidas sobre Cambio Climático (en adelante, GTE-CLP ${ }^{4}$ ), las discusiones acerca de la arquitectura del régimen jurídico internacional sobre el cambio climático, constituido por la Convención Marco de Naciones Unidas sobre el Cambio Climático $^{5}$ (en adelante, CMNUCC) y el Protocolo de Kioto ${ }^{6}$, se han desarrollado por dos caminos separados ${ }^{7}$. Dentro de este two tracking system, el GTE-PK tiene por objeto la redacción de un protocolo que renueve los compromisos de mitigación del Protocolo de Kioto para el período posterior al 2012, mientras que el GTE-CLP tiene la tarea de diseñar un protocolo bajo la Convención que entre otras cosas deberá crear compromisos de mitigación para los países en desarrollo ${ }^{8}$.

\footnotetext{
${ }^{3}$ Durante la XI Conferencia de las Partes de la CMNUCC (COP11) y el primer período de sesiones de la Conferencia de las Partes, que sirvió como reunión de las partes del Protocolo de Kioto (COP/MOP1), que tuvo lugar en 2005 en Montreal, Canadá, se estableció el GTE-PK sobre la base del artículo 3.9 del Protocolo, que ordena la consideración de nuevos compromisos para los Estados integrados en el anexo I al menos siete años antes del final del primer período de compromisos (2012). Vid. Convención Marco de Naciones Unidas sobre el Cambio Climático, Decisión 1/CMP.1 del doc. FCCC/KP/CMP/2005/8/Add.1 de 30 de marzo de 2006, p. 3. Recuperado el 18 de febrero de 2011, de: http://unfccc.int/resource/docs/2005/cmp1/spa/08a01s.pdf\#page=3
}

${ }^{4}$ Durante la XIII Conferencia de las Partes de la CMNUCC (COP13) y el tercer período de sesiones de la Conferencia de las Partes, que sirvió como reunión de las partes del Protocolo de Kioto (COP/MOP3), que se desarrolló en diciembre de 2007 en Bali, Indonesia, se adoptó el Plan de Acción de Bali. Este acuerdo decidió iniciar un proceso global a fin de permitir la aplicación plena, eficaz y sostenida de la CMNUCC mediante la cooperación a largo plazo que se prolongaría más allá del 2012 a fin de adoptar una decisión en el $15 .^{\circ}$ período de sesiones, para el cual se estableció un órgano subsidiario denominado GTE-CLP, que debía concluir su labor en 2009 presentando sus resultados para la revisión y aprobación de la Conferencia de las Partes en su $15 .^{\circ}$ período de sesiones. Vid. Convención Marco de Naciones Unidas sobre el Cambio Climático, Decisión 1/CP.13 del doc. FCCC/CP/2007/6/Add.1 de 14 de marzo de 2008, pp. 3-8. Recuperado el 18 de febrero de 2011, de: http://unfccc.int/resource/docs/2007/cop13/spa/06a01s.pdf\#page=3

${ }^{5}$ BOE núm. 27, de 1 de febrero de 1994.

${ }^{6}$ BOE núm. 33, de 8 de febrero de 2005.

${ }^{7}$ Parece ser que la decisión de tener vías separadas para dar respuesta al cambio climático nace en primer lugar de la voluntad de los países en desarrollo de evitar la imposición de objetivos cuantificados de limitación o reducción de emisiones de GEI, que representarían un límite a su crecimiento, dado que los únicos países que tienen metas cuantificadas señaladas por el Protocolo de Kioto son los países desarrollados, cosa que debería continuar así. Otra razón para la aparición de estas vías paralelas es que EE. UU. adoptó la decisión de eludir los compromisos de reducción vinculantes, lo que dio lugar a la creación de grupos y subgrupos que, si bien están separados, en el fondo trabajan temas conjuntos. Vid. Estrada, R., "Acuerdo de Copenhague: las negociaciones sobre el cambio climático después de la XV Conferencia", óp. cit., p. 113.

${ }^{8}$ Las dos vías desarrolladas por el GTE-PK y el GTE-CLP, al nacer de manera autónoma, despliegan su trabajo sin la cooperación ni la intervención de una sobre la otra, situación que se ve reflejada en la falta de relación existente entre los documentos que cada vía genera, aspecto que pone en riesgo la futura arquitectura del régimen jurídico del cambio climático. 
Dado que en Copenhague no se alcanzó el objetivo establecido en el Plan de Acción de Bali, fue necesario prolongar el mandato de los grupos ad hoc a lo largo de 2010, por lo que se desarrollaron nuevas sesiones de negociación sobre el clima en el seno de ambos grupos. Sin embargo, durante estas sesiones se hizo visible la dificultad para relacionar los textos resultantes del trabajo de ambos grupos, pues la idea de mantener caminos paralelos que produjeran protocolos diferentes constituyó un obstáculo para lograr la cooperación entre ellos a fin de obtener un solo documento final.

Con estas dificultades y debido al ambiente desalentador y de desconfianza que se generó en la COP15, lo que obligaba a mantener un perfil bajo en las negociaciones sobre el clima, entre los días 29 de noviembre y 10 de diciembre de 2010 se celebraron en Cancún (México) las reuniones correspondientes a la XVI Conferencia de las Partes de la Convención Marco de Naciones Unidas sobre Cambio Climático (en adelante, COP16) y la VI Conferencia de las Partes en calidad de reunión de las partes del Protocolo de Kioto (en adelante, COP/MOP6 ${ }^{9}$ ).

Los participantes de la COP16 pretendían mostrar a la comunidad internacional que la labor llevada a cabo a lo largo de 2010 por el GTE-PK y el GTE-CLP sería un ejemplo de inclusión y transparencia, pues se pretendía incluir todas las propuestas que los países desarrollados y en desarrollo habían realizado después de la decepción que había supuesto el Acuerdo de Copenhague a fin de lograr el acuerdo jurídicamente vinculante que todos estaban esperando.

Si bien muchos de los asistentes a la COP16 apostaban por el éxito en las negociaciones, otros anunciaban un nuevo fracaso, el cual no solo retrasaría el proceso, sino también ocasionaría la pérdida de esperanza y confianza de la comunidad internacional hacía la CMNUCC, lo que provocaría que el problema del cambio climático perdiera el espacio que difícilmente había adquirido en las agendas nacionales e internacionales ${ }^{10}$.

\footnotetext{
9 Documento de convocatoria de la COP16 y COP/MOP6, Decisión 13/CP.15 del doc. FCCC/CP/2009/11/Add.1 de 30 de marzo de 2010, p. 46. Recuperado el 18 de marzo de 2011, de http://unfccc.int/resource/docs/2009/cop15/spa/11a01s.pdf\#page=3

${ }^{10}$ Para que el cambio climático fuera considerado como un problema mundial que debía ser afrontado a nivel nacional e internacional se tuvieron que superar una serie de discursos que negaban su existencia. En este sentido, dentro de dichos discursos se encuentran: el antiecologista, que deslegitima a los ecologistas; el que no acepta como real el origen antropogénico del cambio climático, que reúne a científicos que niegan la relación entre las actividades humanas y el cambio climático; y el que no lo considera como uno de los problemas de mayor interés social, pues existirían otras prioridades sociales más urgentes a tratar antes que el cambio climático, como, por ejemplo, el acceso al agua potable o la
} 
Paradójicamente, el ambiente de recelo y desconfianza que rodeaba a los espacios de debate reforzaron el compromiso de los países en la COP16. Pese a que se abrieron para el debate temas que habían sido analizados y acordados anteriormente en Copenhague, lo que generó cierto conflicto entre los países desarrollados y en desarrollo, lo único evidente es que la habilidad y determinación políticas del Gobierno de México y de la secretaria de Relaciones Exteriores de este país y presidenta de la COP, Patricia Espinosa, para inspirar confianza en lograr un acuerdo exitoso demostraron que no todas las esperanzas estaban perdidas y que el "equilibrio" sería la palabra clave durante las negociaciones ${ }^{11}$.

Precisamente por medio de este equilibrio y por la preocupación que los líderes de Estado mostraron tras analizar nuevos informes de especial relevancia, como el informe The Emissions Gap Report del Programa de Naciones Unidas para el Medio Ambiente presentado en noviembre de $2010^{12}$, la COP16 concluyó con la suscripción de los Acuerdos de Cancún, que si bien no incluyen las propuestas de algunos países como

educación. Vid. Garritz, A., Arjonilla, E., "El cambio climático a través del discurso religioso y del discurso políticamente incorrecto", en Revista Educación Química, vol. XIX, núm. 2, 2008, p. 91. Recuperado el 25 de febrero de 2011, de: http://garritz.com/andoni_garritz_ruiz/documentos/67GarritzArjonilla-EQ-2008.pdf

${ }^{11}$ Sobre todo el referido al equilibrio entre los intereses de los países en desarrollo y los de los países desarrollados.

${ }^{12}$ Según el informe elaborado por el Programa de Naciones Unidas para el Medio Ambiente, en el que se analizan los efectos de la promesa hecha por los países en el Acuerdo de Copenhague en relación con la necesidad de lograr fuertes reducciones de las emisiones mundiales que permitan mantener el aumento de la temperatura mundial por debajo de $2{ }^{\circ} \mathrm{C}$, se establece que: "Si se convierten en realidad y se mantienen las más altas aspiraciones expresadas por todos los países en el Acuerdo de Copenhague, las emisiones anuales de gases de efecto invernadero podrían reducirse a una media de unas 7 gigatoneladas (Gt) de $\mathrm{CO}_{2}$ (dióxido de carbono) equivalente para 2020. De no ser así y si las cosas siguen como van, es probable que se registre un aumento de las emisiones del orden de $56 \mathrm{Gt}$ de $\mathrm{CO}_{2}$ equivalente como promedio alrededor de 2020. De todas maneras, una reducción de las emisiones anuales en unas 49 Gt de $\mathrm{CO}_{2}$ equivalente quedaría todavía, sin embargo, a unas $5 \mathrm{Gt}$ por debajo de lo que tendríamos que lograr: una cifra igual a las emisiones totales de los automóviles, autobuses y camiones de todo el mundo en 2005. Esto es así porque los expertos calculan que en 2020 tendrían que registrarse las emisiones de alrededor de $44 \mathrm{Gt}$ de $\mathrm{CO}_{2}$ equivalente para que exista la probabilidad de frenar el aumento de las temperaturas en $2{ }^{\circ} \mathrm{C}$ o menos".

Por esta razón, el informe subraya la complejidad de una serie de situaciones hipotéticas señalando que si se contara con capacidad de dirección, las soluciones al cambio climático podrían ser factibles. Asimismo, este informe establece que en Cancún las medidas sobre financiación, mitigación y adaptación tienen que madurar y avanzar, para demostrar a la sociedad en su conjunto que los gobiernos entienden que en Copenhague quedaron cosas por resolver, pero que siguen manteniendo su compromiso de combatir el cambio climático sin dejar de cumplir unas metas de desarrollo más amplias. Vid. Programa de Naciones Unidas para el Medio Ambiente (PNUMA), Emissions Gap Report. Are the Copenhagen Accord Pledges Sufficient to Limit Global Warming to $2^{\circ}$ C or $1.5^{\circ}$ C? Noviembre de 2010, Nairobi, Kenia pp. 4-5. Recuperado el 3 de febrero de 2011, de http://www.unep.org/publications/ebooks/emissionsgapreport/pdfs/GAP_REPORT_SUNDAY_SINGLE S_LOWRES.pdf 
Bolivia y parecen "desarrollar" el Acuerdo de Copenhague alcanzado un año atrás, demuestran que los Estados continuarán con su lucha contra el cambio climático a través del trabajo colectivo.

\section{LA COP16: UN DIFÍCIL PROCESO DE NEGOCIACIÓN. EL RECHAZO DE BOLIVIA}

Durante la celebración de la COP15 la diversidad de opiniones, la falta de entendimiento y el dominio de las minorías prevalecieron en las negociaciones del clima; sin embargo, en la Conferencia de México se mantuvo una posición constructiva. En este sentido, cuestiones como la mitigación y adaptación ${ }^{13}$, la presentación de informes e inventarios y el segundo período de compromisos de Kioto fueron algunos de los temas que se trataron en distintos foros, donde las partes pudieron manifestar sus inquietudes con vistas a lograr un texto inclusivo y transparente ${ }^{14}$.

Pero el proceso no fue fácil. A lo largo de las negociaciones se presentaron distintos obstáculos y desacuerdos entre las partes, que reclamaban ser escuchadas y tener pleno conocimiento de cualquier documento que se pretendiese adoptar. Así, por ejemplo, Japón rechazaba la posibilidad de renovar el Protocolo de Kioto si no existía un compromiso de reducción de emisiones de países como los Estados Unidos y China, mientras que estos últimos no mostraban ningún interés por lograr un nuevo acuerdo ${ }^{15}$.

Finalmente, después de 12 días de reuniones y negociaciones, el sábado 11 de diciembre los representantes de los Estados que constituyen la CMNUCC decidieron concluir sus

\footnotetext{
${ }^{13}$ La adaptación al cambio climático se refiere a "los ajustes en sistemas humanos o naturales como respuesta a estímulos climáticos proyectados o reales, o sus efectos, que pueden moderar el daño o aprovechar sus aspectos beneficiosos. Se pueden distinguir varios tipos de adaptación, entre ellas la preventiva y la reactiva, la pública y privada, o la autónoma y la planificada. Por su parte, la mitigación es «la intervención antropogénica para reducir las fuentes o mejorar los sumideros de gases de efecto invernadero»". Cfr. Intergovernmental Panel on Climate Change (IPCC), Third Assessment Report: Climate Change, 2001 (TAR). Glossary. Recuperado el 7 de febrero de 2011, de: http://www.ipcc.ch/pdf/glossary/tar-ipcc-terms-sp.pdf

${ }^{14}$ En el marco de la COP16 se desarrollaron una serie de iniciativas de carácter interdisciplinario abiertas al público en general, los medios de comunicación y los delegados acreditados en la COP16, en las que se facilitó el diálogo sobre las ideas y los mecanismos necesarios para afrontar el cambio climático, como el Foro de Comunicación de Cambio Climático, celebrado el 3 de diciembre de 2010, y los Diálogos por el Agua y el Cambio Climático, donde se analizó la importancia de la gestión de los recursos hídricos para la adaptación al cambio climático. Vid. portal oficial de la COP16 http://www.cc2010.mx

15 Vid. Instituto Internacional para el Desarrollo Sostenible (IIDS), "Conferencia de las Naciones Unidas sobre el Cambio Climático: del 29 de noviembre al 10 de diciembre de 2010", en Boletín de Negociaciones de la Tierra, vol. 12, núm. 498, p. 6. Recuperado el 27 de febrero de 2011, de: http://www.iisd.ca/download/pdf/enb12498s.pdf
} 
tareas de negociación formalizando la adopción de un texto de más de 100 páginas denominado los Acuerdos de Cancún, texto que tuvo el apoyo de 193 de los 194 países de la $\mathrm{CMNUCC}^{16}$.

¿Quién era el país 194? ¿Quién se oponía a la adopción de los Acuerdos de Cancún? Una vez más, no todos estaban de acuerdo. El único país que manifestó su desacuerdo fue Bolivia, que no solo se opuso drásticamente al Acuerdo de Copenhague en 2009, sino que incluso en abril de 2010 realizó su propia Cumbre del Clima, la Conferencia Mundial de los Pueblos sobre el Cambio Climático y los Derechos de la Madre Tierra, como una opción paralela a las negociaciones oficiales ${ }^{17}$. Pero ¿cuál era el argumento para dicha oposición? Esta vez Bolivia, uno de los más duros negociadores en esta reunión, se oponía a los Acuerdos de Cancún sobre la base de dos argumentos importantes: la similitud entre el Acuerdo de Copenhague y los Acuerdos de Cancún, y la falta de consenso en las negociaciones.

\section{Los Acuerdos de Cancún, ¿reciclaje del Acuerdo de Copenhague?}

A lo largo del año 2010, el GTE-PK y el GTE-CLP desarrollaron una difícil y maratónica labor a fin de obtener los textos de negociación que debían ser presentados a la COP16 y que debían lograr incluir las propuestas y observaciones que los países desarrollados y en desarrollo habían realizado a lo largo de las cuatro reuniones preparatorias llevadas a cabo en Bonn, Alemania, y Tianjin, China ${ }^{18}$.

Producto de todo el trabajo realizado por los grupos especiales, en diciembre de 2010, previamente a la celebración de la COP16, se logró la redacción de unos documentos

\footnotetext{
${ }^{16}$ Los Acuerdos de Cancún, que comprenden un listado de 26 acuerdos, son un conjunto de iniciativas, instituciones y compromisos dirigidos al futuro que superan al Acuerdo de Copenhague de la COP15.

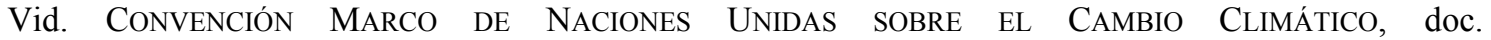
FCCC/CP/2010/7/Add.1; doc. FCCC/CP/2010/7/Add.2; doc. FCCC/KP/CMP/2010/12/Add.1, y doc. FCCC/KP/CMP/2010/12/Add.2 de 15 de marzo de 2011. Recuperados el 20 de marzo de 2011, de: http://unfccc.int/meetings/cop_16/items/5571.php

${ }^{17}$ Esta cumbre fue realizada entre el 19 y el 22 de abril de 2010 en Cochabamba, Bolivia. Dicha reunión fue convocada por el Gobierno de Bolivia al término de la Conferencia de Copenhague bajo el argumento de que el resultado de aquella conferencia había sido un fracaso rotundo, y que, por lo tanto, era la sociedad la que debía brindar una respuesta paralela a la COP15. Vid. Convocatoria de la Conferencia Mundial de los Pueblos sobre el Cambio Climático y los Derechos de la Madre Tierra de 5 de enero de 2010. Recuperado el 15 de febrero de 2010, de: http://cmpcc.org/2010/01/07/convocatoria/\#more-1

${ }^{18} \mathrm{La}$ información relativa a las reuniones preparatorias para la COP16 se encuentra disponible en el portal oficial de la CMNUCC: http://unfccc.int/meetings/intersessional/bonn_10_2/items/5692.php. Última visita, 5 de febrero de 2011.
} 
que parecían ser diferentes del Acuerdo de Copenhague y en los que se incluyeron temas como una posible enmienda del artículo 3.9 del Protocolo de Kioto; mejoras a los mecanismos de flexibilidad y proyectos de uso de la tierra, cambio de uso del suelo y silvicultura; el mantenimiento de un escenario de $1,5^{\circ} \mathrm{C}$ o $2{ }^{\circ} \mathrm{C}$ de incremento máximo de la temperatura, y, la financiación en beneficio de los países en desarrollo para propiciar su adaptación al cambio climático y la mitigación de este ${ }^{19}$.

Sin embargo, después de las primeras reuniones llevadas a cabo en Cancún, el contenido de los textos de negociación fueron cambiando, así como la posición de ciertos países en relación con su contenido. El viernes 10 de diciembre, en la plenaria informal de recapitulación convocada por la presidenta de la COP, se dieron a conocer los textos de proyectos de decisión, que reflejaban el trabajo del GTE-CLP, los cuales no incluían las propuestas ni las observaciones que Bolivia y Venezuela habían presentado anteriormente en las reuniones preliminares ${ }^{20}$. Asimismo, el 11 de diciembre, durante el plenario de cierre de la COP/MOP, el presidente del GTE-PK, John Ashe, informó del trabajo de dicho grupo, cuyos resultados se plasmaban en unos documentos y proyectos de decisión que fueron rechazados por Bolivia bajo el argumento de que posponían la decisión sobre el segundo período de compromisos en el marco del Protocolo de Kioto y posibilitaban la creación de un régimen más flexible y voluntario $^{21}$.

Los documentos puestos a consideración de las partes para su lectura y discusión no solo no incluían temas que algunos países en desarrollo, especialmente Bolivia, habían reclamado durante las reuniones preparatorias a la COP16, sino que además parecían ser documentos de desarrollo del Acuerdo de Copenhague, que tanto malestar había generado durante la COP15. Tal era el descontento con su contenido que el propio jefe

19 Vid. Convención Marco de NACiones Unidas sobre El CAmbio Climático, doc. FCCC/AWGLCA/2010/14 de 13 de agosto de 2010. Recuperado el 30 de noviembre de 2010, de: http://unfccc.int/resource/docs/2010/awglca12/spa/14s.pdf; y doc. FCCC/KP/AWG/2010/17 de 5 de noviembre de 2010. Recuperado el 30 de noviembre de 2010, de: http://unfccc.int/resource/docs/2010/awg15/spa/17s.pdf

${ }^{20}$ El proyecto de decisión sobre el resultado del GTE-CLP enviado por su presidenta, MukahananaSangarwe, a la presidenta de la COP16 para su apoyo y adopción por la COP, aunque fue considerado como un resultado histórico en las negociaciones del clima, fue rechazado por Bolivia, cuya delegación manifestó que no se oponía al consenso que pudiera surgir democráticamente, ni a las posiciones asumidas por las partes, pues su única solicitud era que se le brindara la posibilidad de discutir dichos textos antes de que estos fueran aprobados. Vid. INSTITUTO INTERNACIONAL PARA EL DESARROLLO Sostenible (IIDS), "Conferencia de las Naciones Unidas sobre el Cambio Climático: del 29 de noviembre al 10 de diciembre de 2010", óp. cit., p. 4.

${ }^{21}$ Vid. ibidem, p. 6. 
de la delegación boliviana en la COP16 señaló que "[...] el texto de los países desarrollados es prácticamente el mismo que presentó Estados Unidos (EE.UU.) en la cumbre de Copenhague [...], se presenta de forma más elaborada pero es prácticamente lo mismo 22 ".

Todo este ambiente generado en Cancún parecía retrotraer el proceso de negociación a un año atrás, precisamente a Copenhague, ya que tres de los principales retos de las negociaciones del clima tratados en la COP16 - el objetivo común relativo al aumento de la temperatura media global, la adaptación a las consecuencias del cambio climático y los objetivos de mitigación para el año 2020 - parecían ser finalmente los mismos que proponía el Acuerdo de Copenhague ${ }^{23}$. Por esta razón, la representación boliviana, junto con algunas organizaciones de la sociedad civil, rechazó la adopción de los Acuerdos de Cancún, tal como lo había hecho un año atrás con el Acuerdo de Copenhague, aunque esta vez Bolivia se quedaría sola y sin el apoyo de sus fieles aliados (Ecuador y Venezuela) ${ }^{24}$.

\footnotetext{
${ }^{22}$ Declaraciones realizadas por el jefe de la delegación de Bolivia en la COP16, Pablo Solón, a un día del cierre de las negociaciones del cambio climático. Vid. BBC MUNDO (10 de diciembre de 2010) "Cambio Climático: Bolivia sola contra 193 países". Recuperado el 18 de febrero de 2011, de: http://www.bbc.co.uk/mundo/noticias/2010/12/101211_cumbre_cancun_bolivia_contra_193_paises_pl.sh tml.

${ }^{23}$ Bolivia rechazaba los Acuerdos de Cancún porque afirmaba que estos: a) consignaban como objetivo limitar el incremento de la temperatura a $2{ }^{\circ} \mathrm{C}$, lo que produciría graves impactos como desastres naturales, sequías, pérdida de extensiones forestales, desaparición de Estados insulares, reducción de la producción de alimentos y daños irreversibles a la naturaleza; b) aceptaban promesas de reducción de GEI de los países que oscilaban entre el 13\% y el 17\% según los niveles de 1990, lo que podría provocar que la temperatura aumentara en $4{ }^{\circ} \mathrm{C}$, lo que se contradecía con el compromiso de limitar la temperatura a 2 ${ }^{\circ} \mathrm{C}$; c) habían creado mecanismos de financiación, como el Fondo Verde, y de transferencia de tecnología y adaptación sin tener en cuenta cómo se lograría su financiación; d) fijaban la administración del Fondo Verde del Clima por el Banco Mundial, lo que favorecería únicamente a los países desarrollados y afectaría a la soberanía de los países en desarrollo; e) impulsaban el establecimiento de nuevos mecanismos de mercado, y f) eran un reciclado del mal llamado Acuerdo de Copenhague que hacía un año había sido igualmente rechazado. Vid. portal oficial de la Conferencia Mundial de los Pueblos sobre el Cambio Climático y los Derechos de la Madre Tierra http://cmpcc.org/. Última visita, 20 de febrero de 2011.

${ }^{24}$ Sin embargo, el representante de la delegación boliviana afirmaba que, pese a no haber recibido el apoyo público de las partes en las negociaciones y ser acusados de obstructores, obstinados e irrealistas, en realidad no se sentían solos, ya que no solo algunos delegados de países habían manifestado su solidaridad con la delegación boliviana tras la clausura de la COP16, sino que también habían recibido miles de mensajes de mujeres, hombres y jóvenes representantes de movimientos sociales que apoyaban su postura. Vid. SOlÓN, P., "Why Bolivia stood alone in opposing the Cancun climate agreement", en OUTREACH. A multi-stakeholder magazine on environment and sustainable development, Stakeholder Forum, November 29th - December 10th, p. 5. Recuperado el 5 de mayo de 2011, de: http://www.stakeholderforum.org/sf/outreach/
} 


\section{El consenso, ¿unánime?}

Otro de los argumentos por el que la representación boliviana se negaba a reconocer los Acuerdos de Cancún como documentos oficiales fue la violación de los procedimientos de negociación y la falta de consenso en su aprobación ${ }^{25}$.

El resultado de la COP16 fue celebrado, por la mayoría, como un compromiso histórico y multilateral que recogía varios años de trabajo; aunque, para otros, los acuerdos alcanzados no dejaban de ser manifestaciones débiles e ineficaces ${ }^{26}$. El frente opositor estaba encabezado por Bolivia, firme oponente de los mecanismos basados en el mercado que, a través de su representante, Pablo Solón, presentó al plenario su oposición a la adopción de los Acuerdos de Cancún alegando que, además de su contenido insuficiente para la lucha contra el cambio climático, la falta de consenso impedía que los proyectos de decisión de la COP y la COP/MOP acordados en Cancún fueran adoptados como decisiones oficiales.

Sobre este último punto, el principio fundamental del sistema internacional y de las negociaciones internacionales es el "consenso", principal desafío en cualquier negociación multilateral. Al respecto, es importante aclarar que como forma de aprobar las decisiones dentro del marco de negociaciones del clima el consenso no significa unanimidad $^{27}$. El consenso suele interpretarse como la falta de oposición al acuerdo por parte de los participantes, aunque el grado de aceptación o apoyo a este varíe entre ellos.

25 Vid. Instituto Internacional para el Desarrollo Sostenible (IIDS), "Conferencia de las Naciones Unidas sobre el Cambio Climático: del 29 de noviembre al 10 de diciembre de 2010", óp. cit., p. 17.

${ }^{26}$ La secretaria de la Convención Marco de Naciones Unidas sobre el Cambio Climático, mediante un comunicado de prensa, señaló que la COP16 había llegado a su fin con un paquete equilibrado de decisiones que daban firmeza a la posición de los gobiernos en un futuro bajo de emisiones. Según la secretaria de la CMNUCC, Christiana Figueres, los Acuerdos de Cancún "no representan el final, sino un nuevo comienzo [...] no es lo que se necesitaba finalmente, pero sí representa los cimientos esenciales sobre los cuales se puede construir una mayor ambición colectiva". Vid. CONVENCIÓN MARCO DE NACIONes Unidas sobre el CAmbio Climático. Comunicado de prensa (11 de diciembre de 2010). $\begin{array}{llllll}\text { Recuperado } & \text { el } & 3 & \text { de } & \text { febrero } & \text { de }\end{array}$ http://cadpi.org/Sitio_web/CADPI_files/Comunicado\%20de\%20prensa\%20cierre\%20cop16.pdf

${ }^{27}$ La unanimidad significa que todos los presentes están de acuerdo con un texto y lo suscriben, mientras que el consenso significa que, aunque algunos participantes tengan reparos, estos no son tan grandes ni tan importantes que impidan llegar a un acuerdo en líneas generales sobre el texto; por esta razón, un texto aprobado por consenso no es sometido a votación, ya que podrían ser muchos los países que se opusieran o abstuvieran en la votación. En este sentido, el consenso es definido como la ausencia de una oposición activa. Finalmente, aunque el concepto de consenso no está totalmente claro, cuando se habla de una decisión aprobada por consenso se entiende que ha existido un acercamiento de posiciones. Por ello, al no haberse logrado una aprobación de esa decisión, políticamente se ha optado por un acuerdo global general que evita someter una idea a votación y evitar abstenciones o votos en contra. Vid. FigueroA, P., U., Organismos Internacionales. Ed. Jurídica de Chile, Santiago, Chile, 1991, pp. 105-106. 
En consecuencia, existe una enorme diferencia moral entre un texto aprobado por "unanimidad", donde se requiere el apoyo explícito de todas las partes, y uno aprobado por "consenso", donde, a fin de lograr el consentimiento, el presidente de la COP puede ignorar en algunas ocasiones la objeción de un país ${ }^{28}$.

Precisamente, esto último fue lo que ocurrió en Cancún, donde 193 Estados partes de la CMNUCC, sobre la base de lo dispuesto por los principios y las directrices de las negociaciones internacionales, decidieron aprobar los Acuerdos de Cancún pese a la oposición de Bolivia ${ }^{29}$.

Las críticas de la representación boliviana sobre la falta de consenso en las negociaciones del cambio climático celebradas en Cancún $^{30}$ no impidieron que la presidencia de la COP16, haciendo historia en las negociaciones del clima, lograra que los Acuerdos de Cancún se convirtieran en parte oficial del régimen jurídico del cambio climático, y aunque ordenó que se tomara nota de la objeción presentada por Bolivia ${ }^{31}$, finalmente señaló que “[...] la regla del consenso no puede ser utilizada como un mecanismo de veto", pues “[...] el consenso implica que a todos se les otorgue el

${ }^{28}$ Vid. GUPTA, J., "En nombre de mi delegación..." Un manual para los negociadores del cambio climático de los paises en desarrollo. Centro de Desarrollo Sostenible en las Américas y el Instituto Internacional para el Desarrollo Sustentable, Manitoba, Canadá, 2001, pp. 23-24. Recuperado el 7 de febrero de 2011, de: http://www.iisd.org/cckn/pdf/my_delegation_es.pdf

${ }^{29}$ Al respecto, es importante destacar la Resolución 53/101, de 8 de diciembre de 1998, de la Asamblea de Naciones Unidas, sobre los principios y las directrices para las negociaciones internacionales, donde claramente se establece, entre muchos otros aspectos, que "los Estados deben facilitar la búsqueda o conclusión de negociaciones manteniéndose concentrados en los objetivos principales de esas negociaciones". Vid. AsAMBLEa GenERAL DE LAS NACIONES UnIDAS, Resolución A/RES/53/101, de 20 de enero de 1999, sobre principios y directrices para las negociaciones internacionales. Recuperado el 3 de febrero de 2011, http:/daccess-ddsny.un.org/doc/UNDOC/GEN/N98/775/81/PDF/N9877581.pdf?OpenElement

${ }^{30}$ Las reglas de funcionamiento dadas por la propia CMNUCC para las negociaciones medioambientales engloban dos aspectos importantes: la participación y el consenso. No obstante, el logro de un consenso entre el elevado y diverso número de integrantes que constituyen la CMNUCC es un tema cuando menos complejo. Esto ha llevado a que durante las negociaciones se superen inconvenientes mediante la imaginación y la tenacidad, donde consenso no necesariamente significa unanimidad, sino unidad. Vid. RUBio De URquía, J., "Las negociaciones internacionales sobre el Cambio Climático" en Revista ICE Protocolo de Kioto, núm. 822, mayo 2005, pp. 14-15. Recuperado el 4 de febrero de 2011, de: http://www.revistasice.com/cmsrevistasICE/pdfs/ICE_822_13-

24_9A90CC1CC7CAF18020F590644A305A51.pdf

${ }^{31}$ En este sentido, entre algunas de las líneas establecidas por el Consejo Ejecutivo de la Unesco en relación con el consenso, se ha establecido lo siguiente: "El consenso es el resultado de las concesiones libremente otorgadas y no excluye la expresión de reservas. No obstante, las reservas expresadas en el momento de la adopción de una decisión deberían adjuntarse al texto de toda decisión aprobada por consenso". "La expresión de reservas no debería interpretarse en modo alguno como una no aceptación y, en consecuencia, no debería afectar a la validez de una decisión adoptada por consenso, ni de las obligaciones que de ella se deriven para los Estados miembros". Vid. FigueroA, P. U., Organismos Internacionales, óp. cit., p.106. 
derecho a ser escuchados y que sus posiciones reciban la debida consideración, y a Bolivia se le otorgó esta oportunidad. El consenso no significa que un país tenga el derecho a veto y pueda evitar que otros 193 avancen después de años de negociación sobre algo que nuestras sociedades y las futuras generaciones esperan" 32.

Esta declaración de la presidenta de la COP, aplaudida por la mayoría de los representantes de Estado asistentes, fue rotundamente rechazada por la delegación boliviana, que se quedó al margen del proceso, aunque esto no impidió que el jefe de dicha delegación manifestara su desacuerdo con la Conferencia y anunciara, en nombre y representación del Estado boliviano, la posibilidad de recurrir ante la Corte Internacional de Justicia para impugnar el resultado de la COP16 $6^{33}$.

Si bien es una realidad que los Acuerdos de Cancún no recogen todas las peticiones realizadas por países en desarrollo como Bolivia, que, por ejemplo, exigía la creación de una Corte Internacional de Justicia Climática, sí incluyen otros aspectos reclamados durante muchos años, como la consideración de las comunidades indígenas en las acciones que les puedan afectar relacionadas con el calentamiento global ${ }^{34}$. Este hecho permite señalar que, si bien los Acuerdos no suponen el éxito de las negociaciones -el cual solo se hubiera alcanzado con la suscripción de un documento vinculante que contuviera compromisos de reducción de emisiones de GEI-, su adopción demuestra que el proceso de cooperación internacional llevado a cabo permitió dar un paso adelante en la lucha contra el cambio climático. Sin embargo, es importante tener en cuenta que el acuerdo mayoritario de los Estados que constituyen la CMNUCC no impide la consideración y el análisis de las observaciones y las reclamaciones que se hagan al contenido de los Acuerdos de Cancún u otro documento similar, pues aun con

${ }^{32}$ Vid. portal oficial de la COP16 y COP/MOP6 http://unfccc.int/meetings/cop_16/items/5571.php. Última visita, 20 de marzo de 2011.

${ }^{33}$ Bolivia tiene una posición firme emanada de la CMPCC y adoptada por los movimientos sociales e indígenas que va más allá de lograr un acuerdo que afronte el cambio climático; la meta es que la temperatura no debe subir más allá de $1{ }^{\circ} \mathrm{C}$, lo que se traduce en reducciones drásticas. Lamentablemente, en Cancún esta voz no fue escuchada, lo que marcaría el disenso de los Acuerdos de Cancún. Vid. Conferencia Mundial de los Pueblos sobre el Cambio Climático y los Derechos de la Madre TiERra, "Acuerdo de los Pueblos" de 22 de abril de 2010, Cochabamba, Bolivia. Recuperado el 15 de marzo de 2011, de: http://cmpcc.org/acuerdo-de-los-pueblos/

${ }^{34}$ En los Acuerdos de Cancún, "se reconoce la necesidad de involucrar a una amplia gama de partes interesadas a nivel mundial, regional, nacional y local, ya sean el gobierno central, gobiernos subnacionales y locales, empresas privadas o la sociedad civil, incluidos los jóvenes y las personas con discapacidad, y que la igualdad de género y la participación efectiva de las mujeres y los pueblos indígenas son importantes para la adopción de medidas eficaces en todos los aspectos de cambio climático". Cfr. Convención Marco de Naciones Unidas sobre el Cambio Climático, Decisión 1/CP.16, cit., p. 4. 
opiniones divergentes la única manera de obtener logros importantes es a través de la inclusión, la participación y el acuerdo de todos los países que integran la CMNUCC.

\section{LOS ACUERDOS DE CANCÚN, ¿UNA NUEVA ERA DE COOPERACIÓN INTERNACIONAL?}

Tras el largo y dificultoso camino de las negociaciones, finalmente la COP16 concluyó con la adopción de los Acuerdos de Cancún ${ }^{35}$. Estos acuerdos son decisiones de la Conferencia oficial que anclan los progresos realizados en la doble vía de negociación de la Convención y el Protocolo de Kioto en los últimos años.

Si bien los acuerdos alcanzados en la COP16 no pueden ser considerados como un compromiso demasiado ambicioso debido a que no establecen obligaciones vinculantes de reducción de emisiones de GEI tal como hace el Protocolo de Kioto, estos acuerdos, sobrepasando toda expectativa, han logrado que los mayores emisores de GEI como EE. UU. y China se incorporen al marco de las negociaciones del clima ${ }^{36}$. Dicha participación ha sido importante para conciliar las posturas de los diferentes países que constituyen la CMNUCC, lo que ha permitido recobrar la confianza que se había perdido en el proceso $^{37}$.

Estos acuerdos proponen trabajar en dos esferas importantes: la mitigación (reduciendo los impactos) y la adaptación a los impactos previsibles (facilitando la ayuda necesaria a

35 Vid. CONVEnción Marco De NACiones Unidas SOBRe El CAMBio Climático, doc. FCCC/CP/2010/7/Add.1; doc. FCCC/CP/2010/7/Add.2; doc. FCCC/KP/CMP/2010/12/Add.1 y doc. FCCC/KP/CMP/2010/12/Add.2 de 15 de marzo de 2011. Recuperados el 20 de marzo de 2011, de: http://unfccc.int/meetings/cop_16/items/5571.php

${ }^{36}$ Vid. KOYANA, K., "COP16 Cancun Agreement and Future Domestic/Overseas Challenges Regarding Global Warming Issue" en Special Bulletin. A Japanese Perspective on International Energy Landscape (23), Institute of Energy Economics, Japón, diciembre de 2010.

${ }^{37}$ Uno de los aspectos relevantes que impulsó a los representantes de los Estados a llegar a un acuerdo durante las negociaciones de la COP16 fue la postura de Japón de abandonar el Protocolo de Kioto si los países desarrollados no asumían compromisos vinculantes. Por otro lado, mientras que la Unión Europea apostaba por la continuidad del Protocolo de Kioto y la obtención de un acuerdo de reducción de emisiones ambicioso hasta el 2020, el "grupo paraguas" integrado por los Estados Unidos, Australia, Canadá, Noruega y Kazajistán se negaba a firmar cualquier compromiso si este no incluía a los países con economías emergentes. Por su parte, China y el G-77 apoyaban la continuidad del Protocolo, aunque la atención estuvo centrada en el grupo bolivariano formado por Bolivia, Venezuela y Ecuador, que apostaban por incrementar los compromisos de Kioto y promover mayores transferencias de dinero a los países en desarrollo. Vid. Instituto InTERnACiOnal PARA EL Desarrollo Sostenible (IIDS), "Conferencia de las Naciones Unidas sobre el Cambio Climático: del 29 de noviembre al 10 de diciembre de 2010”, óp. cit., pp. 1-33. 
los países con mayor grado de vulnerabilidad y promoviendo la transferencia de tecnologías limpias a fin de lograr la reducción de emisiones que el planeta precisa).

Desde una perspectiva general, la Decisión 1/CP16, que contiene el trabajo del GTECLP y que representa el mayor avance logrado, incluye aspectos relativos a una visión compartida para la cooperación a largo plazo sobre la adaptación, mitigación, financiación, tecnología y creación de capacidades. Asimismo, esta decisión amplía el trabajo del GTE-CLP durante el 2011 a fin de desarrollar las medidas adoptadas en esta, y mueve a la discusión y el debate sobre las opciones legales para las futuras negociaciones del clima, cuyos resultados deberán presentarse en la COP17. Por su parte, la Decisión 1/CMP6, que refleja el trabajo del GTE-PK, acuerda que dicho grupo continuará trabajando sobre aspectos que son de su competencia hasta lograr que los resultados sean aprobados lo antes posible para evitar una brecha entre el primer y el segundo período de compromisos ${ }^{38}$. En esta decisión también destacan las promesas de las partes del anexo I de la CMNUCC sobre sus metas de reducción de emisiones y se insta a que estas sean en el futuro mayores y más ambiciosas ${ }^{39}$. A continuación, tomando en cuenta la importancia de los aspectos desarrollados en los Acuerdos de Cancún, se analizan los principales resultados obtenidos en la COP16, que incluyen decisiones en el ámbito de los dos procesos: la cooperación a largo plazo y el Protocolo de Kioto.

\section{Mitigación}

En la COP16, las partes de la CMNUCC reconocieron de manera conjunta que el aumento de la temperatura media global no puede superar $\operatorname{los} 2{ }^{\circ} \mathrm{C}$ respecto a los niveles preindustriales, y acordaron que para el 2015 se pueda realizar una revisión de estos niveles con vistas al establecimiento de un nuevo límite de $1,5^{\circ} \mathrm{C}$ en función de los

\footnotetext{
${ }^{38}$ El trabajo del GTE-PK que será desarrollado a lo largo de 2011 se basará en los proyectos contenidos en el texto del documento FCCC/KP/AWG/CRP.4/Rev.4., cuyo contenido engloba aspectos sobre las enmiendas del Protocolo de Kioto de conformidad con el artículo 3, párrafo 9.3; el uso de la tierra, el cambio de uso de la tierra y la silvicultura; el comercio de emisiones y los mecanismos basados en proyectos; los gases de efecto invernadero, los sectores y las categorías de fuentes, la absorción por los sumideros, y otras cuestiones metodológicas; el examen de la información sobre las posibles consecuencias ambientales, económicas y sociales, incluidos los efectos secundarios, de los instrumentos, políticas, medidas y metodologías a disposición de las partes. Vid. CONVENCIÓN MARCO DE NACIONES UnidAS SOBRE EL CAMBIO CLIMÁTICO, doc. FCCC/KP/AWG/CRP.4/Rev.4 de 10 de diciembre de 2010. Recuperado el 28 de febrero de 2011, de: http://unfccc.int/resource/docs/2010/awg15/eng/crp04r04.pdf

${ }^{39}$ Vid. Convención Marco de NACiones UnidAs sobre el CAMBio Climático, Decisión 1/CMP.6, cit., p. 4.
} 
informes que el Grupo Intergubernamental de Expertos sobre Cambio Climático o Intergovernmental Panel on Climate Change (en adelante, IPCC por sus siglas en inglés) pueda emitir ${ }^{40}$.

De igual forma, en los Acuerdos de Cancún se reconoce que la lucha contra el cambio climático es un reto para los gobiernos centrales, locales y regionales y para la sociedad civil en general, que deben impulsar un cambio del actual paradigma de desarrollo descontrolado hacia un desarrollo bajo en carbono en el que los derechos de las personas, sobre todo de las mujeres y los pueblos indígenas, sean debidamente respetados ${ }^{41}$.

Por otro lado, los países desarrollados reconocieron oficialmente sus objetivos en un proceso multilateral y se comprometieron a crear planes y estrategias de desarrollo bajos en carbono evaluando la mejor manera de hacerlo, incluyendo para ello la utilización de los mecanismos de mercado. Asimismo, se comprometieron a reportar anualmente sus inventarios sobre emisiones de GEI y a presentar información cada dos años acerca de sus metas de reducción de emisiones, sus acciones de mitigación y el apoyo brindado a los países en desarrollo ${ }^{42}$.

Igualmente, en el proceso multilateral se reconocieron las acciones de los países en desarrollo para reducir sus emisiones e informar de ellas a la Secretaría de la CMNUCC, para lo que se creó un registro que relaciona y registra sus acciones. Mientras que las acciones de mitigación realizadas con fondos nacionales solo están sujetas a monitoreo interno, las acciones que tengan apoyo financiero internacional deben ser notificadas cada dos años al estar sujetas a un proceso de revisión y monitoreo internacional. Asimismo, se incorporó un sistema internacional de consulta y análisis de dichos informes a cargo del Órgano Subsidiario de Implementación de la $\mathrm{CMNUCC}^{43}$.

En cuanto al sistema de información, con el objetivo de dar transparencia al proceso, los países en desarrollo se comprometieron a presentar sus comunicaciones nacionales cada

\footnotetext{
${ }^{40}$ El objetivo principal del IPCC es analizar, de forma exhaustiva, objetiva, abierta y transparente, la información científica, técnica y socioeconómica relevante para entender los elementos científicos del riesgo que supone el cambio climático provocado por las actividades humanas, sus posibles repercusiones y las posibilidades de adaptación y atenuación de este. Véase portal oficial del IPCC: http://www.ipcc.ch

${ }^{41}$ Cfr. Convención Marco de Naciones Unidas sobre el Cambio Climático, Decisión 1/CP.16, cit., p. 4.

${ }^{42}$ Vid. ibídem, p.8.

${ }^{43}$ Vid. ibídem, p. 11.
} 
cuatro años, así como sus inventarios nacionales cada dos años, los cuales estarán sujetos a un análisis a través de un proceso de consulta internacional, no intrusiva, no punitiva y respetuosa con su soberanía nacional ${ }^{44}$.

\section{Financiación}

En relación con la financiación, los Acuerdos de Cancún establecen tres vías ${ }^{45}$ :

- Un "fondo de arranque", que deriva del compromiso adquirido por los países desarrollados en el Acuerdo de Copenhague de movilizar 30.000 millones de dólares estadounidenses entre el 2011 y el 2012 para cubrir los gastos de adaptación y mitigación de los países en desarrollo.

- Una financiación a "largo plazo"; los países desarrollados asumieron el compromiso de movilizar hasta el 2020 la suma de 100.000 millones de dólares estadounidenses a través de distintas fuentes de ingresos para que los países en desarrollo adopten medidas de mitigación y adaptación.

- Un "fondo verde del clima", que será una entidad operativa del mecanismo financiero de la Convención y que funciona bajo su dirección. El objetivo del Fondo Verde del Clima es el apoyo a proyectos, programas y otras actividades en los países en desarrollo, utilizando para ello diferentes fuentes de financiación y repartiendo fondos, pero sin generarlos. Según los Acuerdos de Cancún, este fondo, que contará con una secretaría independiente, estará dirigido por una junta de 24 miembros que representarán de forma equitativa a los países desarrollados y en desarrollo que constituyen la CMNUCC. De su administración, sujeta a revisión pasados tres años desde su puesta en funcionamiento, se encarga un fideicomisario que interinamente será el Banco Mundial. Asimismo, el diseño de dicho fondo estará a cargo de un comité transitorio formado por 40 miembros para la elección de sus autoridades de acuerdo con lo establecido en el anexo III de la Decisión $1 / \mathrm{COP} 16^{46}$.

\footnotetext{
${ }^{44}$ Vid. Convención Marco de Naciones Unidas sobre el Cambio Climático, Decisión 1/CP.16, cit., pp. 2 , 7-11.

${ }^{45}$ Vid. ibídem, pp. 16-18.

${ }^{46}$ Vid. Convención Marco de Naciones Unidas sobre el Cambio Climático, Decisión 1/CP16, cit., p. 29.
} 


\section{Mecanismo de tecnología}

En Cancún se llegó a un acuerdo sobre un nuevo mecanismo de tecnología ${ }^{47}$, que incluye el Comité Ejecutivo sobre Tecnología ${ }^{48}$ y el Centro y Red de Tecnología del Clima, para aumentar la cooperación tecnológica apoyando las acciones de mitigación y adaptación, con lo que se da el primer paso hacia la promoción del uso de energías limpias a nivel mundial ${ }^{49}$.

- El Comité Ejecutivo sobre Tecnología tendrá como funciones principales: a) realizar un panorama de las necesidades tecnológicas y analizar las cuestiones políticas y técnicas; b) recomendar medidas para promover la transferencia de tecnologías; c) facilitar la colaboración entre gobiernos, el sector privado, las organizaciones no gubernamentales y las comunidades académicas y de investigación; d) recomendar medidas para evitar las barreras que dificultan la transferencia de tecnología, y e) buscar cooperación para la transferencia de tecnologías.

- Por su parte, el Centro y Red de Tecnología del Clima, a petición de los países en desarrollo, deberá coordinar un grupo de redes, organizaciones e iniciativas con vistas a involucrar a estos países brindando asesoramiento y apoyo para la identificación de las necesidades tecnológicas y su implementación ambientalmente racional, así como para la coordinación de capacidades, el apoyo en la identificación de opciones técnicas y el despliegue de las tecnologías existentes. Asimismo, este centro debe facilitar las alianzas entre actores del sector público y el privado, dar asistencia técnica y capacitación a los países, e identificar herramientas analíticas, políticas y de mejores prácticas y ayudar a su desarrollo $^{50}$

\footnotetext{
${ }^{47}$ Vid. ibidem, pp. 18-21.

${ }^{48}$ La composición y el mandato de este comité están incluidos en el anexo IV de la Decisión 1/CP16, pp. 30-31.

${ }^{49}$ Vid. ibídem, pp. 19-20.

${ }^{50}$ Vid. Convención Marco de Naciones Unidas sobre el CAmbio Climático, Decisión 1/CP16, cit., pp. 20-21.
} 


\section{Mecanismo REDD ${ }^{51}$}

Para muchos de los asistentes a la COP16, el logro más importante de esta reunión fue el establecimiento de un marco para la creación del mecanismo REDD+, el cual deberá ser apoyado por los países desarrollados, quienes a su vez adquieren el compromiso de apoyar a los países en desarrollo financiando las medidas de protección de sus bosques $^{52}$.

En los Acuerdos de Cancún se establece que, en el caso de que se brinde apoyo adecuado y predecible para este mecanismo, los países en desarrollo deberán aspirar a frenar, parar y revertir la pérdida de cobertura forestal y la emisión de carbono, y se les alienta a que contribuyan con las medidas de mitigación del sector forestal. Dichas medidas comprenderían la reducción de las emisiones debidas a la deforestación y la degradación de los bosques, la conservación de las coberturas forestales, la gestión sostenible de los bosques y el incremento de las reservas forestales de carbono. Para este fin, los países en desarrollo deberán elaborar estrategias nacionales o planes de acción, niveles de referencias forestales nacionales y subnacionales, monitoreos forestales y todo un sistema de provisión de información de este proceso ${ }^{53}$.

La implementación de este mecanismo contempla como condición salvaguardar la condición de los bosques tropicales garantizando una distribución equitativa entre las partes interesadas y reconociendo plenamente los derechos de los pueblos indígenas y las comunidades campesinas donde el mecanismo se ejecute ${ }^{54}$.

Si bien se establece que la financiación de los proyectos REDD+ se obtendrá mediante mecanismos multilaterales y bilaterales ya existentes, también se dispone que en el

\footnotetext{
${ }^{51}$ El Programa Reducing Emissions from Deforestation and Forest Degradation "plus" Conservation, the Sustainable Management of Forests and Enhancement of Forest Carbon Stocks (REDD+, por sus siglas en inglés) se refiere a cuestiones relativas a la reducción de las emisiones derivadas de la deforestación y la degradación de los bosques en los países en desarrollo, y a la función de la conservación y la gestión sostenible de los bosques y el aumento de las reservas forestales de carbono en los países en desarrollo. Vid. Convención Marco de Naciones Unidas sobre el CAmbio Climático, Decisión 2/CP.13 del doc. FCCC/CP/2007/6/Add.1 de 14 de marzo de 2008, p. 11. Recuperado el 20 de marzo de 2011, de: http://unfccc.int/resource/docs/2007/cop13/spa/06a01s.pdf\#page $=8$

52 Vid. Instituto Internacional para el Desarrollo Sostenible (IIDS), "Conferencia de las Naciones Unidas sobre el Cambio Climático: del 29 de noviembre al 10 de diciembre de 2010", óp. cit., p. 20.

${ }^{53}$ Vid. Convención Marco de Naciones Unidas sobre el Cambio Climático, Decisión 1/CP16 cit., Guía y Salvaguardas de los proyectos REDD+, anexo I, pp. 26-27.

${ }^{54}$ Vid. ibídem.
} 
futuro tendrán que analizarse nuevas opciones de financiación que el GTE-CLP deberá proponer en la próxima COP $17^{55}$.

\section{Mercado de carbono}

Ante la falta de objeción manifiesta, los Acuerdos de Cancún, tanto los documentos acordados por el GTE-CLP como por el GTE-PK, establecen de manera implícita que los mercados de carbono permanecerán activamente hasta después de la conclusión del primer período de compromisos del Protocolo de Kioto, es decir, después de $2012^{56}$.

En lo que respecta al trabajo desarrollado por el GTE-CLP, las partes decidieron estudiar y promover el establecimiento en la próxima COP17 de uno o más mecanismos de mercado a fin de mejorar la eficacia en función de los costes que pueden suponer las medidas de mitigación teniendo en cuenta el fomento de la participación voluntaria de las partes, la complementación de las medidas de mitigación con otros medios de apoyo conveniente para cada país en desarrollo, las salvaguardas de integridad ambiental, la adopción de medidas tendentes a evitar las emisiones mundiales de GEI, etc. ${ }^{57}$

Bajo el GTE-PK, las partes acordaron que el comercio de los derechos de emisiones y los mecanismos basados en proyectos del Protocolo de Kioto seguirán a la disposición de las partes del anexo I como medios para lograr sus objetivos de limitación y reducción de emisiones. En este sentido, las partes decidieron cuestiones relativas al gobierno y los aspectos técnicos del mecanismo para un desarrollo limpio del Protocolo de Kioto (en adelante, MDL ${ }^{58}$ ) que históricamente han generado retrasos en el proceso de registro y aprobación de proyectos, abriendo la posibilidad de establecer en la próxima COP a celebrarse en Durban un procedimiento de apelación frente a las

\footnotetext{
${ }^{55}$ Vid. Convención Marco de Naciones Unidas sobre el Cambio Climático, Decisión 1/CP16, cit., p. 13.

56 Vid. Instituto Internacional para el Desarrollo Sostenible (IIDS), "Conferencia de las Naciones Unidas sobre el Cambio Climático: del 29 de noviembre al 10 de diciembre de 2010”, óp. cit. p. 6.

${ }^{57}$ Vid. Convención Marco de Naciones Unidas sobre el Cambio Climático, Decisión 1/CP16, cit., pp. $15-$ 16

${ }^{58}$ El mecanismo para un desarrollo limpio es un mecanismo de flexibilidad creado por el Protocolo de Kioto cuya característica principal y elemento diferenciador radica en el hecho de ser el único de los mecanismos que permite la participación de países en desarrollo en acciones de mitigación de emisiones de GEI. Para un mayor análisis de este mecanismo, véase MEJíA, C., "Mecanismo de Desarrollo Limpio: Una debilidad convertida en oportunidad", en Pensamiento y gestión: Revista de la División de Ciencias Administrativas de la Universidad del Norte, núm. 18, Colombia, 2005, pp. 138-139.
} 
decisiones de la Junta Ejecutiva del MDL a fin de mejorar la transparencia en el proceso y con ello subsanar los posibles errores suscitados durante su tramitación ${ }^{59}$.

En relación con la distribución regional y subregional de los proyectos del MDL, los Acuerdos de Cancún insisten en la necesidad de conseguir una mayor distribución a nivel global de estos proyectos, razón por la que se aprobaron un plan de préstamo para invertir en actividades del MDL que está disponible para los países con menos de 10 proyectos inscritos en la $\mathrm{CMNUCC}^{60}$, así como el apoyo al uso de líneas de base estandarizadas -que pueden ser presentadas por empresas, organizaciones internacionales u observadores a través de la autoridad nacional del país receptor- para ayudar a reducir los costes de transacción, aumentar la transparencia y agilizar el proceso de aprobación en el MDL ${ }^{61}$.

Aunque la mejora de los procedimientos y las técnicas del MDL son aspectos importantes dentro de los Acuerdos de Cancún, uno de los puntos más significativos es la aceptación de la elegibilidad de la captura y secuestro de carbono en formaciones geológicas (en adelante, CSC) como una actividad de compensación dentro del MDL ${ }^{62}$. Por acuerdo de las partes, los proyectos de CSC pueden ser elegibles, pero no a corto plazo, siempre que se respeten criterios de seguridad y rigor desde el punto de vista ambiental. Para el análisis de dichos aspectos, se encomendó a los órganos correspondientes el desarrollo de las modalidades y los procedimientos que permitan la inclusión de esta nueva modalidad de proyectos del MDL para su aprobación en la $\mathrm{COP} / \mathrm{MOP}^{63}$.

\footnotetext{
${ }^{59}$ Vid. Convención Marco de Naciones Unidas sobre el Cambio Climático, Decisión 3/CMP.6 del doc. FCCC/KP/CMP/2010/12/Add.2, cit., p. 4

${ }^{60}$ Vid. ibidem, pp. 6, 8 y 13.

${ }^{61}$ Los Acuerdos de Cancún definen la línea de base estandarizada como "una línea de base establecida para una parte o un grupo de partes para facilitar el cálculo de la reducción de las emisiones y absorciones y/o la determinación de la adicionalidad de las actividades de proyectos del mecanismo para un desarrollo limpio, mientras provea asistencia para asegurar la integridad medioambiental". Vid. ibídem.

${ }^{62}$ La captura y secuestro de carbono es el "proceso de aumento del contenido en carbono de un depósito de carbono que no sea la atmósfera. Desde un enfoque biológico incluye el secuestro directo de dióxido de carbono de la atmósfera mediante un cambio en el uso de las tierras, forestación, reforestación y otras prácticas que mejoran el carbono en los suelos agrícolas. Desde un enfoque físico incluye la separación y eliminación del dióxido de carbono procedente de gases de combustión o del procesamiento de combustibles fósiles para producir fracciones con un alto contenido de hidrógeno y dióxido de carbono, y el almacenamiento a largo plazo bajo tierra en depósitos de gas y petróleo, minas de carbón y acuíferos salinos agotados". Cfr. Grupo Intergubernamental de Expertos sobre Cambio Climático (IPCC), Third Assessment Report: Climate Change, 2001 (TAR). Anexo B. Glossary, óp. cit., p.195.

${ }^{63} \mathrm{El}$ acuerdo sobre esta inclusión fue posible gracias al cambio de posición de los miembros de la AOSIS (Alliance of Small Island States o Alianza de Pequeños Estados Insulares, coalición de 43 países insulares
} 


\section{Adaptación}

La adaptación fue otro de los aspectos que mayor importancia tuvo durante las negociaciones en Cancún, y obtuvo un lugar preferente en la agenda ${ }^{64}$.

En este sentido, se estableció el llamado Marco de Cancún para la Adaptación, que busca mejorar las medidas y los proyectos de adaptación en los países en desarrollo a través de la cooperación internacional relativa a financiamiento y apoyo técnico. Igualmente se aprobó la creación de un comité de adaptación y un programa de trabajo sobre pérdida y daño ${ }^{65}$.

En el caso del Marco de Cancún para la Adaptación, el acuerdo invita a las partes a mejorar las acciones de adaptación mediante: a) la planificación e implementación de acciones de adaptación en los procesos de planificación nacional; b) el análisis sobre el impacto, la vulnerabilidad y las medidas de adaptación; c) el fortalecimiento de las capacidades institucionales, y d) el desarrollo y la transferencia de tecnologías y mejora del acceso a la información relacionada con el clima.

En cuanto al Comité de Adaptación, se promueve la implementación de medidas de adaptación basadas en: a) el apoyo y la orientación técnica; b) la mejora de la información sobre buenas prácticas; c) el fortalecimiento de la participación de organizaciones, centros y redes, y d) la consideración de las comunicaciones de las partes de la CMNUCC sobre el monitoreo y las acciones de adaptación a fin de sugerir otras más eficientes ${ }^{66}$.

\footnotetext{
de tierras bajas y pequeñas dimensiones, en su mayoría miembros del G-77, que son particularmente vulnerables a la subida del nivel del mar), cuyos miembros tradicionalmente se han opuesto a la CSC. Sin embargo, a pesar de este cambio de actitud, aún se mantienen las preocupaciones legítimas sobre la seguridad de la CSC, razón por la que el Organismo Subsidiario para Asesoramiento Científico y Tecnológico de la CMNUCC deberá desarrollar las modalidades y los procedimientos para la inclusión de esta nueva modalidad de proyectos de MDL, con vistas a su aprobación en la COP17. Vid. Convención Marco de Naciones Unidas sobre el Cambio Climático, Decisión 7/CMP.6 del doc. FCCC/KP/CMP/2010/12/Add.2, cit., p. 29.

${ }^{64}$ Los aspectos relativos a la adaptación fueron debatidos durante las negociaciones ministeriales que tuvieron lugar en el marco del GTE-CLP y el GTE-PK en Cancún, donde las representaciones de España y Argelia llevaron a cabo los procesos de consulta en relación con la creación de nuevos mecanismos de adaptación. Vid. INSTITUTO INTERNACIONAL PARA EL DESARROLlO SOSTENIBLE (IIDS), "Conferencia de las Naciones Unidas sobre el Cambio Climático: del 29 de noviembre al 10 de diciembre de 2010”, óp. cit., p. 16.

${ }^{65}$ Vid. Convención Marco de Naciones Unidas sobre el Cambio Climático, Decisión 1/CP.6 cit. pp. 4-7.

${ }^{66}$ Vid. ibídem, pp. 5-6.
} 
Finalmente, en relación con el programa de trabajo sobre pérdida y daño, las partes de la CMNUCC decidieron que este debe permitir establecer en el futuro un programa que ayude a cubrir los daños producidos por el cambio climático en los países en desarrollo, manteniendo un trato especial y diferenciado para aquellos que padezcan eventos climáticos extremos ${ }^{67}$.

\section{Creación y fortalecimiento de capacidades}

En cuanto a la creación de capacidades, los Acuerdos de Cancún establecen que el apoyo debe ser promovido a través del fortalecimiento de las instituciones pertinentes, la comunicación, la educación y la sensibilización, así como a través de la participación de todos los actores, con el fin de facilitar que los países en desarrollo puedan hacer frente de forma efectiva al reto del cambio climático y responder a sus compromisos de la mejor manera posible. Para este cometido, se aprueba que las partes del anexo II de la CMNUCC otorguen los recursos financieros necesarios ${ }^{68}$.

\section{Revisión}

En relación con la revisión, las partes de la CMNUCC decidieron la revisión periódica de la adecuación del objetivo global de reducción de emisiones a largo plazo así como el progreso general para lograrlo. Esta revisión deberá guiarse por los principios de equidad y responsabilidades comunes pero diferenciadas y capacidades respectivas, debiendo rendirse cuenta de: a) la mejor ciencia disponible, incluyendo los informes de evaluación del IPCC; b) los impactos del cambio climático observados, y c) la consideración del fortalecimiento del objetivo global a largo plazo, incluso en relación con el aumento de temperatura de $1,5^{\circ} \mathrm{C}$. La primera revisión comenzará el 2013 y concluirá el $2015^{69}$.

\footnotetext{
${ }^{67}$ Vid. Ibídem.

${ }^{68}$ Vid. Convención Marco de Naciones Unidas sobre el Cambio Climático, Decisión 1/CMP.6, anexo, cit., p. 27-28.

${ }^{69}$ Vid. Convención Marco de Naciones Unidas sobre el Cambio Climático, Decisión 1/CP16 cit., p. 23.
} 


\section{Otros asuntos}

Finalmente, se puede destacar la consideración de tres aspectos importantes dentro de los Acuerdos de Cancún:

- El mandato del GTE-CLP fue ampliado por un año para llevar a cabo las tareas incluidas en los Acuerdos de Cancún, principalmente la concerniente al funcionamiento del Mecanismo Tecnológico para 2012. Asimismo, dicho grupo deberá continuar trabajando a partir de los documentos que están bajo su consideración y continuará discutiendo las opciones jurídicas con vistas a completar un resultado basado en el Plan de Acción de Bali, las conclusiones de la COP16 y las propuestas que las partes han realizado en el marco del artículo 17 de la $\mathrm{CMNUCC}^{70}$.

- Aunque no se establecieron los compromisos de reducción de emisiones de las partes del anexo I de la CMNUCC, el texto del GTE-PK "toma nota" de las promesas voluntarias de reducción cuantificada de emisiones para todos los sectores de la economía que deberán ser implementadas por las partes del anexo I de la CMNUCC, debiendo basarse en las recomendaciones emitidas por el Cuarto Informe de Evaluación del $\mathrm{IPCC}^{71}$.

- Asimismo, los Acuerdos deciden la extensión de las negociaciones para el 2011, año en el que se realizará la COP17 en Durban, y ordena que hasta la fecha de su realización se discutan las opciones legales del acuerdo final para la prosecución de los objetivos de la CMNUCC.

\section{A MANERA DE CONCLUSIONES: ¿QUÉ DEJA CANCÚN Y QUÉ SE ESPERA EN DURBAN?}

Si bien los Acuerdos de Cancún promovieron la consecución de logros importantes en materia de cambio climático, es evidente que no representan un acuerdo jurídicamente

\footnotetext{
${ }^{70}$ El artículo 17 de la CMNUCC señala que: 1. La Conferencia de las Partes podrá, en cualquier período ordinario de sesiones, aprobar protocolos de la Convención. 2. La Secretaría comunicará a las partes el texto de cada proyecto de protocolo al menos seis meses antes de la celebración de ese período de sesiones. 3. Las condiciones para la entrada en vigor del protocolo serán establecidas por ese instrumento. 4. Solo las partes en la Convención podrán ser partes en un protocolo. 5. Solo las partes en un protocolo podrán adoptar decisiones de conformidad con ese protocolo.

${ }^{71}$ El Cuarto Informe de Evaluación puede consultarse a través del portal oficial del IPCC, http://www.ipcc.ch
} 
vinculante que establezca objetivos de reducción de emisiones de GEI para los países desarrollados, razón principal por la que mereció el rechazo de Bolivia.

La inclusión de temas menos controvertidos en el fondo de estos acuerdos solo permite evidenciar que se ha desplazado la resolución de cuestiones más difíciles y complejas, como la forma jurídica del resultado de la próxima convención (una decisión de la COP o un nuevo protocolo), o el establecimiento de un segundo período de compromisos del Protocolo de Kioto para la COP17 que se realizará en Durban (Sudáfrica) en diciembre de 2011.

Entonces ¿cuál es el avance en las negociaciones del clima? Ciertamente no todo salió mal. El proceso desarrollado en la COP16 sirvió para dar impulso a nuevas negociaciones transparentes e incluyentes en relación con las cuestiones referidas al cambio climático. El apoyo de 193 países es una muestra de ello.

Además, los acuerdos alcanzados muestran el compromiso de los países por recortar sus emisiones con el fin de mantener el aumento de la temperatura mundial por debajo de 2 ${ }^{\circ} \mathrm{C}$, lo que podría suponer que en la próxima conferencia de las partes los Estados se comprometan a objetivos más estrictos.

Los Acuerdos de Cancún no solo incluyen las metas de mitigación de los países desarrollados, sino que también introducen las medidas de mitigación de los países en desarrollo, lo que supone un avance en el compromiso mundial de reducción de emisiones de GEI. El consenso en temas como la verificación permite evidenciar que los Acuerdos de Cancún consentirán que las acciones de mitigación sean parte importante de las agendas nacionales de las partes que constituyen la CMNUCC.

La creación de novedosos mecanismos para la lucha contra el cambio climático, como el Fondo Verde del Clima, el Marco para la Adaptación de Cancún, el Mecanismo de Tecnología o el Mecanismo REDD+, es una muestra de que en las negociaciones se pueden conciliar los planteamientos y las ideologías de los países en desarrollo, aunque ello solo se logre si se exige poco a los países desarrollados.

Pese a estos avances significativos, todavía existe mucho camino por recorrer. En el caso del Fondo Verde del Clima, por ejemplo, si bien se establece que será un fondo que repartirá recursos financieros a los países en desarrollo, no se especifica cómo se generarán estos recursos ni si se admitirá la participación del sector privado; por otro lado, se otorga la administración temporal al Banco Mundial, olvidando que este 
organismo ha sido y es duramente rechazado por países en desarrollo, que lo alinean a los intereses de los países desarrollados.

De igual forma, se establece la creación del Mecanismo de Tecnología para facilitar la transferencia efectiva de las tecnologías apropiadas a los países en desarrollo, pero esta no parece ser una cuestión concluida, pues aspectos como los derechos de propiedad intelectual de las nuevas tecnologías no han sido desarrollados en los Acuerdos de Cancún, lo que podría obstaculizar el inicio de las tareas de este mecanismo.

En cuanto a los mecanismos de mercado, se aceptó la inclusión de la CSC (apoyada principalmente por el Grupo Paraguas y la Organización de Países Exportadores de Petróleo - banco central del mercado petrolero-), pero no se establecieron los procedimientos ni las modalidades para su aceptación, lo que sin duda ocupará un gran espacio en la agenda de la próxima COP17. Lo mismo ocurre con el mecanismo REDD+, un mecanismo polémico y rechazado por las organizaciones ambientales y los pueblos indígenas durante muchos años, donde será importante la consideración de las salvaguardas ambientales y sociales en el momento de definir su funcionamiento y financiación. La inclusión de disposiciones para financiar las actividades del REDD+ a través de un mecanismo de mercado podría haber puesto todo el proceso en riesgo, razón por la que se dejó esta cuestión a decisión de los gobiernos, quienes deberán explorar las opciones de financiación antes de la próxima COP17. Lo importante será que este mecanismo no sea utilizado por los países desarrollados como una limpieza de imagen o una simple contribución ambiental a través de plantaciones forestales, sino que sea un verdadero medio para luchar contra el cambio climático y no un mero mecanismo de mercado.

Con todo, la principal tarea en la COP16 fue la recuperación de la confianza en el proceso de negociación, y este paso está dado. Ahora la tarea fundamental de la COP17 será que los Estados, de manera conjunta y considerando cada una de las posiciones existentes, alcancen un acuerdo ambicioso y vinculante que signifique una verdadera solución al problema del cambio climático, acuerdo en el que no solo se establezcan compromisos de reducción de emisiones que frenen el calentamiento global, sino que además demuestre a las presentes y futuras generaciones que los Estados están plenamente comprometidos con la lucha contra un problema cuya causa principal, con mayor o menor participación, implica a toda la sociedad internacional. 


\section{BIBLIOGRAFÍA}

\section{REFERENCIAS DOCTRINALES}

ESTRADA, R., "Acuerdo de Copenhague: las negociaciones sobre el cambio climático después de la XV Conferencia", en Revista del Centro de Economía Internacional, núm. 17, 2010. Recuperado el 22 de septiembre de 2010, de: http://www.cei.gov.ar/revista/17/parte5b.pdf

FIGUEROA, P. U., Organismos Internacionales. Ed. Jurídica de Chile, Santiago, Chile, 1991.

GARRITZ, A.; ARJONILLA, E., "El cambio climático a través del discurso religioso y del discurso políticamente incorrecto”, en Revista Educación Química, vol. XIX, núm. 2, 2008. Recuperado el 25 de febrero de 2011, de: http://garritz.com/andoni_garritz_ruiz/documentos/67Garritz-Arjonilla-EQ-2008.pdf

GUPTA, J., "En nombre de mi delegación..." Un manual para los negociadores de cambio climático de los países en desarrollo. Centro de Desarrollo Sostenible en las Américas y el Instituto Internacional para el Desarrollo Sustentable, Manitoba, Canadá, 2001. Recuperado el 7 de febrero de 2011, de: http://www.iisd.org/cckn/pdf/my_delegation_es.pdf

KOYANA, K., "COP16 Cancun Agreement and Future Domestic/Overseas Challenges Regarding Global Warming Issue", en Special Bulletin. A Japanese Perspective on International Energy Landscape (23), Institute of Energy Economics, Japón, diciembre de 2010.

MEJÍA, C., "Mecanismo de Desarrollo Limpio: Una debilidad convertida en oportunidad", en Pensamiento y gestión: Revista de la División de Ciencias Administrativas de la Universidad del Norte, núm. 18, Colombia, 2005.

RUBIO DE URQUIA, J., "Las negociaciones internacionales sobre el Cambio Climático" en Revista ICE Protocolo de Kioto, núm. 822, mayo de 2005. Recuperado el 4 de febrero de 2011, de: http://www.revistasice.com/cmsrevistasICE/pdfs/ICE_822_13-

24 9A90CC1CC7CAF18020F590644A305A51.pdf 
SOLÓN, P., "Why Bolivia stood alone in opposing the Cancun climate agreement", en OUTREACH, a multi-stakeholder magazine on environment and sustainable development, Stakeholder Forum, 29 de noviembre - 10 de diciembre, p. 5. Recuperado el 5 de mayo de 2011, de: http://www.stakeholderforum.org/sf/outreach/

\section{REFERENCIAS NORMATIVAS}

Convención de Viena sobre el Derecho de los Tratados, de 23 de mayo de 1969 (BOE núm. 142, de 13 de junio de 1980).

Convención Marco de Naciones Unidas sobre el Cambio Climático (BOE núm. 27, de 1 de febrero de 1994).

Protocolo de Kioto de la Convención Marco de las Naciones Unidas sobre el Cambio Climático (BOE núm. 33, de 8 de febrero de 2005).

\section{REFERENCIAS DOCUMENTALES}

ASAMBLEA GENERAL DE LAS NACIONES UNIDAS, Resolución A/RES/53/101, de 20 de enero de 1999, sobre principios y directrices para las negociaciones internacionales. Recuperado el 3 de febrero de 2011, de: http://daccess-ddsny.un.org/doc/UNDOC/GEN/N98/775/81/PDF/N9877581.pdf?OpenElement

BBC MUNDO (10 de diciembre de 2010), "Cambio Climático: Bolivia sola contra 193 países". Recuperado el 18 de febrero de 2011, de: http://www.bbc.co.uk/mundo/noticias/2010/12/101211_cumbre_cancun_bolivia_contra _193_paises_pl.shtml

CONFERENCIA MUNDIAL DE LOS PUEBLOS SOBRE EL CAMBIO CLIMÁTICO Y LOS DERECHOS DE LA MADRE TIERRA, "Convocatoria de la Conferencia Mundial de los Pueblos sobre el Cambio Climático y los Derechos de la Madre Tierra”, de 5 de enero de 2010. Recuperado el 15 de febrero de 2011, de: http://cmpcc.org/2010/01/07/convocatoria/\#more-1

"Comunicado del Estado Plurinacional de Bolivia: Las propuestas de Cochabamba van a Cancún”, de 10 de octubre de 2010. Recuperado el 16 de febrero de 
2011, de: http://cmpcc.org/2010/10/10/comunicado-del-estado-plurinacional-debolivia/\#more-2397

"Acuerdo de los Pueblos", de 22 de abril de 2010, Cochabamba, Bolivia. Recuperado el 15 de marzo de 2011, de: http://cmpcc.org/acuerdo-de-los-pueblos/

CONVENCIÓN MARCO DE NACIONES UNIDAS SOBRE EL CAMBIO CLIMÁTICO, Decisión 1/CMP.1 del doc. FCCC/KP/CMP/2005/8/Add.1 de 30 de marzo de 2006. Recuperado el 18 de febrero de 2011, de: http://unfccc.int/resource/docs/2005/cmp1/spa/08a01s.pdf\#page=3

Decisiones 1/CP.13 y 2/CP.13 del doc. FCCC/CP/2007/6/Add.1 de 14 de marzo de 2008. Recuperado el 20 de marzo de 2011, de: http://unfccc.int/resource/docs/2007/cop13/spa/06a01s.pdf\#page=3

Decisión 2/CP.15 “Acuerdo de Copenhague”, del doc. FCCC/CP/2009/11/Add.1 de 30 de marzo de 2010. Recuperado el 5 de enero de 2011, de: http://unfccc.int/resource/docs/2009/cop15/spa/11a01s.pdf\#page $=4$

Decisión 13/CP.15 del doc. FCCC/CP/2009/11/Add.1 de 30 de marzo de 2010. Recuperado el 18 de marzo de 2011, de http://unfccc.int/resource/docs/2009/cop15/spa/11a01s.pdf\#page=3

Doc. FCCC/AWGLCA/2010/14 de 13 de agosto de 2010. Recuperado el 30 de noviembre de 2010, de: http://unfccc.int/resource/docs/2010/awglca12/spa/14s.pdf

Doc. FCCC/KP/AWG/2010/17 de 5 de noviembre de 2010. Recuperado el 30 de noviembre de 2010, de: http://unfccc.int/resource/docs/2010/awg15/spa/17s.pdf

Doc. FCCC/KP/AWG/CRP.4/Rev.4 de 10 de diciembre de 2010. Recuperado el 28 de febrero de 2011, de: http://unfccc.int/resource/docs/2010/awg15/eng/crp04r04.pdf

Doc. FCCC/CP/2010/7/Add.2; doc. FCCC/CP/2010/7/Add.3; doc. FCCC/KP/CMP/2010/12/Add.1 y doc. FCCC/KP/CMP/2010/12/Add.2, "Cancun Agreements", de 15 de marzo de 2011. Recuperados el 20 de marzo de 2011, de: http://unfccc.int/meetings/cop_16/items/5571.php

Comunicado de Prensa, de 11 de diciembre de 2010. Recuperado el 3 de febrero de 2011, de: http://cadpi.org/Sitio_web/CADPI files/Comunicado\%20\%20cop16.pdf 
GRUPO INTERGUBERNAMENTAL DE EXPERTOS SOBRE CAMBIO CLIMÁTICO (IPCC), Third Assessment Report: Climate Change 2001 (TAR). Glossary. Recuperado el 7 de febrero de 2011, de: http://www.grida.no/climate/ipcc_tar/vol4/spanish/pdf/wg3sum.pdf INSTITUTO INTERNACIONAL PARA EL DESARROLLO SOSTENIBLE (IIDS), “Conferencia de las Naciones Unidas sobre el Cambio Climático: del 29 de noviembre al 10 de diciembre de 2010”, en Boletín de Negociaciones de la Tierra, vol. 12, núm. 498, 2010. Recuperado el 27 de febrero de 2011, de: http://www.iisd.ca/download/pdf/enb12498s.pdf

PROGRAMA DE NACIONES UNIDAS PARA EL MEDIO AMBIENTE (PNUMA), Emissions Gap Report. Are the Copenhagen Accord Pledges Sufficient to Limit Global Warming to $2^{\circ}$ C or $1.5^{\circ}$ C?, Nairobi, Kenia, 2010. Recuperado el 3 de febrero de 2011, de:

http://www.unep.org/publications/ebooks/emissionsgapreport/pdfs/GAP_REPORT_SU NDAY_SINGLES_LOWRES.pdf 


\section{ANEXO I: SIMILITUDES ENTRE EL ACUERDO DE COPENHAGUE Y LOS ACUERDOS DE CANCÚN}

\begin{tabular}{|c|c|}
\hline Acuerdo de Copenhague ${ }^{72}$ & Acuerdos de Cancún 73 \\
\hline $\begin{array}{c}\text { "2. Convenimos en que se requieren fuertes } \\
\text { reducciones de las emisiones mundiales, a la luz de } \\
\text { la ciencia y de la información recogida en el Cuarto } \\
\text { Informe de Evaluación del IPCC, con vistas a lograr } \\
\text { una disminución de dichas emisiones que permita } \\
\text { mantener el aumento de la temperatura mundial por } \\
\text { debajo de } 2 \stackrel{\circ}{\circ} \text {, y nos proponemos tomar medidas } \\
\text { para cumplir este objetivo..." }\end{array}$ & $\begin{array}{l}\text { “4. Reconocemos además que se requieren recortes } \\
\text { en las emisiones globales de gases de efecto } \\
\text { invernadero de acuerdo con la ciencia, y como se } \\
\text { documenta en el Cuarto Informe de Evaluación del } \\
\text { IPCC, con el fin de reducir las emisiones globales } \\
\text { de gases de efecto invernadero para mantener el } \\
\text { aumento de la temperatura mundial por debajo de } 2 \\
\text { C [...] y que las partes debemos adoptar medidas } \\
\text { urgentes para cumplir este objetivo..." }\end{array}$ \\
\hline $\begin{array}{c}\text { "6. Somos conscientes de la importancia } \\
\text { fundamental de reducir las emisiones debidas a la } \\
\text { deforestación y la degradación forestal y de la } \\
\text { necesidad de aumentar la absorción de gases de } \\
\text { efecto invernadero por los bosques, y convenimos } \\
\text { [...] ofrecer incentivos positivos para esas } \\
\text { actividades mediante el establecimiento inmediato } \\
\text { de un mecanismo que incluya actividades de } \\
\text { REDD+..." }\end{array}$ & $\begin{array}{c}\text { "70. Alentamos a los países partes en desarrollo a } \\
\text { contribuir con las medidas de mitigación en el } \\
\text { sector forestal mediante la realización de } \\
\text { actividades [...]: a) reducción de las emisiones de la } \\
\text { deforestación; b) reducción de las emisiones de la } \\
\text { degradación; c) conservación de las reservas } \\
\text { forestales de carbono 10; d) gestión sostenible de } \\
\text { los bosques; e) mejoramiento de las reservas de } \\
\text { carbono de los bosques.” }\end{array}$ \\
\hline $\begin{array}{c}\text { “8. [...] Los países desarrollados se comprometen } \\
\text { colectivamente a suministrar recursos nuevos y } \\
\text { adicionales [...] por un valor de aproximadamente } \\
30.000 \text { millones de dólares de los EE. UU. para el } \\
\text { período de 2010-2012, con una distribución } \\
\text { equilibrada entre la adaptación y la mitigación. Se } \\
\text { dará prioridad a la financiación para la adaptación } \\
\text { destinada a los países en desarrollo más } \\
\text { vulnerables [...] los países desarrollados se } \\
\text { comprometen al objetivo de movilizar conjuntamente } \\
\text { 100.000 millones de dólares de los EE. UU. anuales } \\
\text { para el año } 2020 \text { con el fin de atender las } \\
\text { necesidades de los países en desarrollo.” }\end{array}$ & $\begin{array}{c}\text { "95. Tomamos nota del compromiso colectivo de } \\
\text { los países desarrollados de proporcionar recursos } \\
\text { nuevos y adicionales [...] de aproximadamente } \\
30.000 \text { millones de dólares de los EE. UU. para el } \\
\text { período 2010-2012, con una distribución equilibrada } \\
\text { entre la adaptación y mitigación; se dará prioridad a } \\
\text { la financiación para la adaptación de los países en } \\
\text { desarrollo más vulnerables..." } \\
\text { "98. Reconocemos que las partes que son países } \\
\text { desarrollados se comprometen [...] al objetivo de la } \\
\text { movilización conjunta de } 100.000 \text { millones de } \\
\text { dólares de los EE. UU. anuales para el año } 2020 \\
\text { para atender las necesidades de los países en } \\
\text { desarrollo." }\end{array}$ \\
\hline $\begin{array}{l}\text { "10. Decidimos que se establecerá el Fondo Verde } \\
\text { de Copenhague para el Clima como una de las } \\
\text { entidades encargadas del funcionamiento del } \\
\text { mecanismo financiero de la Convención, con el } \\
\text { objeto de apoyar proyectos, programas, políticas y } \\
\text { otras actividades de los países en desarrollo } \\
\text { relacionadas con la mitigación [...] y la adaptación." }\end{array}$ & $\begin{array}{l}\text { "102. Decidimos establecer un Fondo Verde del } \\
\text { Clima, para ser designado como entidad encargada } \\
\text { del funcionamiento del mecanismo financiero de la } \\
\text { Convención en [...], para apoyar los proyectos, los } \\
\text { programas, las políticas y otras actividades de las } \\
\text { partes que son países en desarrollo..." }\end{array}$ \\
\hline $\begin{array}{l}\text { “11. A fin de intensificar la labor de desarrollo y } \\
\text { transferencia de tecnología, decidimos establecer } \\
\text { un Mecanismo Tecnológico para acelerar el } \\
\text { desarrollo y la transferencia de tecnología en apoyo } \\
\text { de la labor de adaptación y mitigación...” }\end{array}$ & $\begin{array}{c}\text { "117. Decidimos establecer un Mecanismo } \\
\text { Tecnológico para facilitar la aplicación de acciones } \\
\text { para lograr el objetivo mencionado en los párrafos } \\
\text { 113-115, bajo la dirección y responsabilidad de la } \\
\text { Conferencia de las Partes..." }\end{array}$ \\
\hline
\end{tabular}

72 Vid. CONVEnción Marco de NaCiones Unidas sobre el CAMBIo Climático, Decisión 2/CP.15 Acuerdo de Copenhague, del doc. FCCC/CP/2009/11/Add.1 de 30 de marzo de 2010. Recuperado el 5 de marzo de 2010, de: http://unfecc.int/resource/docs/2009/cop15/spa/11a01s.pdf\#page=4

73 Vid. Convención Marco de Naciones Unidas sobre el Cambio Climático, "Cancun Agreements". Decisión 1/CP.16. Recuperado el 10 de febrero de 2011, de: http://unfccc.int/meetings/cop_16/items/5571.php 


\section{ANEXO II: ELEMENTOS PRIMORDIALES DE LOS “ACUERDOS DE CANCÚN"}

\begin{tabular}{|c|c|}
\hline Decisiones de la COP & Decisiones de la COP/MOP \\
\hline $\begin{array}{c}\text { Objetivo de } 2{ }^{\circ} \mathrm{C}^{74} \text { que figura por primera vez como } \\
\text { decisión de la COP. }\end{array}$ & $\begin{array}{l}\text { Acuerdo para continuar y concluir las negociaciones } \\
\text { a fin de evitar una brecha entre el primer y el } \\
\text { segundo período de compromisos. }\end{array}$ \\
\hline $\begin{array}{l}\text { Las promesas de reducción de emisiones del } \\
\text { Acuerdo de Copenhague por primera vez son } \\
\text { ancladas como una decisión de la COP. }\end{array}$ & $\begin{array}{l}\text { Se acordó el año base para el cálculo de las } \\
\text { reducciones de emisiones: } 1990 .\end{array}$ \\
\hline $\begin{array}{c}\text { Se acordó mejorar el monitoreo, la presentación de } \\
\text { informes y la verificación, así como las consultas } \\
\text { internacionales y el análisis de los procedimientos } \\
\text { para todos los países. }\end{array}$ & $\begin{array}{c}\text { Aprobación de que las partes puedan utilizar un año } \\
\text { base de referencia opcional para cumplir sus } \\
\text { propios fines. }\end{array}$ \\
\hline $\begin{array}{l}\text { Establecimiento del Marco de Adaptación y del } \\
\text { Comité de Adaptación. }\end{array}$ & $\begin{array}{c}\text { Acuerdo para que los países desarrollados puedan } \\
\text { seguir usando el comercio de emisiones y los } \\
\text { mecanismos basados en proyectos para el } \\
\text { cumplimiento de sus objetivos de reducción de } \\
\text { emisiones. }\end{array}$ \\
\hline $\begin{array}{c}\text { Creación de nuevos órganos climáticos de } \\
\text { financiación: Fondo Verde del Clima, Comité de } \\
\text { Transición (para el diseño del Fondo) y Comité } \\
\text { Permanente (para supervisar y coordinar los flujos } \\
\text { de financiación del Fondo). }\end{array}$ & $\begin{array}{c}\text { Acuerdo para que las actividades forestales y de } \\
\text { uso de la tierra sigan siendo utilizadas por los } \\
\text { países desarrollados para el cumplimiento de sus } \\
\text { objetivos. }\end{array}$ \\
\hline $\begin{array}{c}\text { Establecimiento de un nuevo Mecanismo de } \\
\text { Tecnología, que comprende el Comité Ejecutivo } \\
\text { sobre Tecnología y el Centro y Red de Tecnología } \\
\text { del Clima. }\end{array}$ & $\begin{array}{l}\text { Acuerdo para que el potencial calentamiento global } \\
\text { producido por los gases de efecto invernadero sea } \\
\text { previsto por el IPCC. }\end{array}$ \\
\hline \multicolumn{2}{|l|}{$\begin{array}{l}\text { Fijación de los elementos marco y clave para el } \\
\text { desarrollo del mecanismo REDD+. }\end{array}$} \\
\hline \multicolumn{2}{|l|}{$\begin{array}{l}\text { Acuerdo para considerar durante la COP17 el } \\
\text { establecimiento o no de nuevos mecanismos } \\
\text { basados en mercados. }\end{array}$} \\
\hline $\begin{array}{l}\text { Realizar un seguimiento adecuado de los esfuerzos } \\
\text { mundiales de mitigación que los países } \\
\text { desarrollados y en desarrollo implementen. }\end{array}$ & \\
\hline
\end{tabular}

\footnotetext{
${ }^{74} \mathrm{El}$ objetivo de $2{ }_{-}^{\circ} \mathrm{C}$ se refiere al incremento máximo de la temperatura media mundial (por encima de los niveles de la era preindustrial).
} 